\title{
Mechanical Investigation of a Novel Ceramic Composite Consisting of the YAG Matrix With Alumina Nanoparticles Fabricated by Slip Casting and the Conventional Sintering Process
}

\author{
Mohammad Torki \\ University of Isfahan \\ behrooz movahedi ( $\sim$ b.movahedi@ast.ui.ar) \\ Isfahan University \\ S S. ghazanfari \\ Isfahan University of Technology \\ M. Milani \\ Iranian Research Organization for Science and Technology
}

\section{Research Article}

Keywords: Ceramic-matrix composites, Nano-structures, hardness, Slip casting

Posted Date: June 30th, 2020

DOI: https://doi.org/10.21203/rs.3.rs-38134/v1

License: (c) (1) This work is licensed under a Creative Commons Attribution 4.0 International License.

Read Full License 


\section{Abstract}

The aim of this study was to fabricate YAG/Al203 ceramic composites with different alumina nanoparticles using slip casting and the atmospheric sintering process. In addition, some mechanical properties such as hardness and elastic modules of this novel ceramics were evaluated using the nanoindention technique. The results showed that the rheological behavior of the slurry was optimized to the solid loading of $55 \mathrm{wt} \%$ and the relative density of the green body was enhanced up to $65 \%$. Relative density was increased after sintering at $1700{ }^{\circ} \mathrm{C}$ for $12 \mathrm{~h}$ to $99.5 \%$ and the pore size $(150 \mathrm{~nm})$ was reduced to half of that of powder particles. It should be noted that the optimum amount of alumina nanoparticles as a reinforcing agent in the matrix was less than $5 \% \mathrm{wt}$ and the composite hardness was increased to $7.3 \%$, as compared to the pure YAG ceramic.

\section{Introduction}

Advanced ceramic composites consisting of $\mathrm{Al}_{2} \mathrm{O}_{3} / \mathrm{Y}_{3} \mathrm{Al}_{5} \mathrm{O}_{12}$ have been used in aerospace engineering, such as components for the jet motors of the airplane industry and machining tools [1-3]. Alumina is one of the most common materials. Its good mechanical properties, particularly fracture toughness, can be improved by the second phase additions. Creep behavior and mechanical properties of alumina ceramics can be improved by dispersing yttrium aluminum garnet (YAG) inclusion in the alumina matrix [4]. The presence of the YAG phase increases the hardness of the composite, as compared to the pure alumina [5]. Some studies have successfully developed $\mathrm{Al}_{2} \mathrm{O}_{3} / \mathrm{YAG}$ composites with a low yttria dopant by slip casting and injection molding. Sommer and et al. [6] studied alumina composites containing 5, 10 and 20 vol\% YAG with a slip casting process. Alumina composite with 10 vol\% YAG had the best mechanical properties, so further increase of the YAG phase did not result in an increase of mechanical properties. Due to the prevention of the YAG particles penetrating process, the density of the samples was decreased. Previous studies have been focused on developing $\mathrm{Al}_{2} \mathrm{O}_{3} / \mathrm{YAG}$ composites by dry axial pressing [7] or isostatic pressing [8].

Less work has, however, been done on the mixtures of YAG and alumina [9-12]. Slip casting is a simple method that can produce a homogeneous and dense green body [13-15], especially for multiple or composite systems. Homogenization of suspensions and the slurry rheological behavior play an important role in determining the process of slip casting and the microstructure of the final product [16]. A dispersed slurry can be obtained by choosing an optimal concentration of the dispersant [17]. In some systems, the rise of linear density with increasing the solid load has been observed, although there is no relationship between solid loading and green density in the systems $[18,19]$. It has been reported that the porosity distribution of slip-cast green body depends on the properties of the slurry, such as rheological properties and solid loading of the suspension [20]. These researchers have investigated many effective parameters, such as the effects of the dispersant concentration and solid loading content on the rheological behavior of YAG slurries and mechanical properties. 
In all of these studies, YAG has been used to improve the mechanical properties of the alumina composites. The purpose of this study was, therefore, to increase the hardness of the YAG matrix by adding the alumina nanoparticles. However, the effects of solid loading on the rheological behavior of slurry in the slip casting process and sintered bodies, as well as the mechanical properties, have not yet been evaluated for the $\mathrm{YAG} / \mathrm{Al}_{2} \mathrm{O}_{3}$ composites. The fracture surface and hardness of ceramic composites with 2, 5 and $8 \%$ wt alumina nanoparticles were investigated in detail.

\section{Experimental Procedure}

High-purity a- $\mathrm{Al}_{2} \mathrm{O}_{3}$ nanoparticles $\left(99.99 \%, 50 \mathrm{~nm}\right.$, US-Nano Research) and $\mathrm{Y}_{2} \mathrm{O}_{3}(99.99 \%, 70 \mathrm{~nm}$, Baikowski SAS-France) were used as the raw materials. Yttria powder was dissolved in a high-purity nitric acid to obtain the transparent solution of $\mathrm{Y}\left(\mathrm{NO}_{3}\right)_{3}$. Briefly, $\mathrm{Y}\left(\mathrm{NO}_{3}\right)_{3}$ and urea (Merck.99.5\%) were dissolved in distilled water to make a solution. Urea was applied as a precipitating agent at a ratio of 33:1 urea: $\mathrm{Y}^{+3}$. The $\mathrm{a}-\mathrm{Al}_{2} \mathrm{O}_{3}$ nanoparticles solution was added to the mixed solution and dispersed using ultrasonication. The mixed turbid liquid with a ratio of $\mathrm{Y} / \mathrm{Al}=3 / 5$ was homogenized using a hot plate magnetic stirrer at $90^{\circ} \mathrm{C}$ for $3 \mathrm{~h}$. The suspension was washed with a suction filter, 3 times with deionized water, and 1 time with ethanol. The powder was dried in an oven at $100^{\circ} \mathrm{C}$, for $24 \mathrm{~h}$. Then, the powder was calcined at $1550{ }^{\circ} \mathrm{C}$ for $3 \mathrm{~h}$ to synthesize the YAG phase [21, 22]. YAG nanocomposite powders containing 2,5 and $8 \%$ wt alumina nanoparticles were compound using the high-energy planetary ball-milling. Alumina balls $(10 \mathrm{~mm})$ were used. The milling duration was $2 \mathrm{~h}$ and the ratio of the ball/powder was $5 / 1$ (by weight); the ratio of ethanol/powder was $3 / 1$.

Ammonium polyacrylate (Dolapix CE64, Zschimmer \& Schwarz Chemical Co., Ltd. Germany) was used as the dispersant. The optimum amount of the dispersant was obtained by plotting viscosity as a function of the dispersant concentration. For viscosity measurement, a rotary viscometer was used (Model LVDV-II; Brookfield, Middleboro, USA). The viscosity of the slurry was measured by a rotational stress-controlled rheometer with a shear rate of $264 \mathrm{~s}^{-1}$.

A 3D-mixture (Savis sanat Sepehr Iranian) was also used to homogenize the slurry. The slurries were milled for 3, 6, 9 and $12 \mathrm{~h}$ with the ball (half of them were $10 \mathrm{~mm}$ and the others were $5 \mathrm{~mm}$ ) ratio of 1:3 (by weight) and at the speed of $45 \mathrm{rpm}$. After slip casting, the bodies were dried in the air and the organic additives were removed by heating the samples at $600^{\circ} \mathrm{C}$ for $2 \mathrm{~h}$ in the air. The density of the green bodies was measured by the Archimedes method, using deionized water as the immersion medium [23]. The pore size distribution of the slip-cast samples was carried out using mercury porosimetry (PoreSizer 9320, Micromeritics Instrument Corp, USA).

The microstructure of the composite powders before and after ball-milling was studied using field emission scanning electron microscopy (FESEM, TESCAN, MIRA3, Czech Republic). The calcined synthesized composite powder at $1550^{\circ} \mathrm{C}$ was characterized using a Philips XPERT MPD X-ray diffractometer with $\mathrm{Cu}$-Ka radiation. Ceramic composite samples were sintered at $1700^{\circ} \mathrm{C}$ for $12 \mathrm{~h}$ in the air atmosphere furnace (AZAR-F3L 1800, Iran). The microstructures of the $\mathrm{YAG} / \mathrm{Al}_{2} \mathrm{O}_{3}$ composite after 
sintering were examined on the fracture surfaces using scanning electron microscopy (SEM, JEOL 6510). Finally, the indentation test was performed on the $Y A G / \mathrm{Al}_{2} \mathrm{O}_{3}$ composite samples and the pure $\mathrm{YAG}$ using CSM nanoindenter instruments (SA, Peseux, Switzerland) with a Berkovich diamond tip (less than $10 \mathrm{~nm}$ in diameter, type 4/03). In the employed load schedules, the load at the constant rate was first ramped up to a peak value of $40 \mathrm{mN}$ and then unloaded. Each test was performed three times. The standard of this method is ASTM E2546 [24].

\section{Results And Discussion}

\section{1. $\mathrm{Y}_{3} \mathrm{Al}_{5} \mathrm{O}_{12}$ powder characterization}

The X-ray diffraction pattern of the YAG powder is shown in Fig. 1. According to the diffraction pattern, YAG (00-033-0040 JCPDS file) was formed. Fig. 2. (a and $\mathbf{b})$ shows the field emission scanning electron microscope (FESEM) images of the $\mathrm{YAG} / \mathrm{Al}_{2} \mathrm{O}_{3}$ nanocomposite powder before and after milling. After milling, the agglomerates were broken and less agglomeration would be suitable for slip casting because the particle size distribution was effective in determining the results of density and pore size distribution.

\section{- Rheological behavior of the slurry and the relative density of the green body}

Fig. 3 illustrates the viscosity of $55 \%$ wt of $\mathrm{YAG} / \mathrm{Al}_{2} \mathrm{O}_{3}$ nanocomposite slurries versus the shear rate at different dispersant percentages. Dolapix CE64 was a dispersant stabilizing the suspension by forming a thin layer around the ceramic powder. As the negative charge on the surface of particles prevented their agglomeration, the Brownian motion could overcome the attraction force $[25,26]$. The viscosity was decreased with increasing the shear rates. The slurry showed a pseudo-plastic behavior (the viscosity of slurries was decreased with increasing the shear rates) [27]. This behavior would be desirable for many ceramic forming methods because the suspension is flowing in high tensions; however, after removing the stress, they can retained their shape. When the amount of the dispersant Dolapix CE64 was $1 \% \mathrm{wt}$, the viscosity was minimum. By increasing the amount of the dispersant beyond the optimum value, the viscosity was increased due to the formation of a polymer network resulting from the additional dispersant within the slurry. Therefore, in order to create a slurry with suitable viscosity, the dispersant value should be optimized. Slurry behavior indicated that the powder was de-agglomerated and the dispersant was absorbed on the particle surface, leading to the creation of the stable slurry. The forces (electrostatic and steric) between the particles should be large enough to prevent the compaction of the particles due to the presence of van-der-Waals forces [28]. The method of slurry preparation is one of the key elements in slip casting; this is because slip casting can be used to fabricate green bodies with higher density [29]. Slurry stability has the most effect on the microstructure of the green body. The dispersed slurry did not contain agglomerations and it was stabilized by electrostatic or steric mechanisms to create a high-density green body.

As shown in Fig. 4, the viscosity of the $\mathrm{YAG} / \mathrm{Al}_{2} \mathrm{O}_{3}$ nanocomposite slurries was measured at various times with $55 \%$ wt solid load. Primary agglomerates tended to prevent the exit of water from the cavity channels 
between particles. This caused a less amount of the dispersant to flow; so, it could not cover the particles surface very well and remained unsaturated in the particles surface. Viscosity was increased at higher solid loads. Therefore, at hard and large agglomerates, the dispersant had no effective role. By increasing the de-agglomeration time, big and hard agglomerates were broken and viscosity began to decrease. Therefore, the dispersant could saturate the surface of all particles $[13,30]$. According to Fig. 4 , the optimum de-agglomeration time was $9 \mathrm{~h}$ to achieve the minimum viscosity.

Fig. 5 shows the viscosity of $55 \% w t \mathrm{YAG} / 2-8 \% \mathrm{wt} \mathrm{Al}_{2} \mathrm{O}_{3}$ nanocomposite slurries versus different shear rates. By raising the amount of alumina (above $2 \% \mathrm{wt}$ ) in the slurry, due to the agglomeration of alumina particles, the viscosity was increased. As a result, slurries with high-viscosity could not be suitable for slip casting.

Fig. 6 shows the pore size distribution of the green bodies obtained by slip casting for three different samples. YAG-8 \%wt $\mathrm{Al}_{2} \mathrm{O}_{3}$ had two peaks. The maximum peak happened at the pore size of $150 \mathrm{~nm}$, while the other peak happened at a larger size. This behavior was due to the formation of agglomerates in the slurry [31]. For YAG-2 \%wt $\mathrm{Al}_{2} \mathrm{O}_{3}$ and YAG-5 \%wt $\mathrm{Al}_{2} \mathrm{O}_{3}$, a peak was obtained almost at half of the particle size due to the appropriate density. However, the pores of YAG-5 $\% \mathrm{wt} \mathrm{Al}_{2} \mathrm{O}_{3}$ were larger than YAG$2 \% w t$. Therefore, the maximum green relative density of YAG-2 \%wt was higher than YAG- $5 \% \mathrm{wt} \mathrm{Al}_{2} \mathrm{O}_{3}$ $[32,33]$.

\subsection{Phase and microstructural characterization of sintered body}

Fig. 7 shows the XRD pattern of the YAG/ $/ \mathrm{Al}_{2} \mathrm{O}_{3}$ ceramic containing YAG (00-033-0040 JCPDS file) and $\mathrm{Al}_{2} \mathrm{O}_{3}$ (01-75-1862 JCPDS file). This sample was sintered at $1700{ }^{\circ} \mathrm{C}$ for $12 \mathrm{~h}$ in the air atmosphere furnace. Fig. 8 shows the relative densities of $Y A G / 2-8 \% w t ~ \mathrm{Al}_{2} \mathrm{O}_{3}$ composites before and after sintering versus different solid loads. By raising the solid loads, in all samples, the green density was increased to the optimal viscosity of the slurry. By further increasing the solid load, the viscosity was raised due to the agglomeration. Agglomeration formed large pores, thereby decreasing density [9,34]. As can be seen, the sample YAG-2 \%wt $\mathrm{Al}_{2} \mathrm{O}_{3}$ had the highest green relative density. It could be attributed to the least viscosity of this sample, such that the green relative density was increased from $47 \%$ to $65 \%$. After sintering in the air atmosphere at $1700{ }^{\circ} \mathrm{C}$ for $12 \mathrm{~h}$, the relative final density was increased from $75 \%$ to $99.5 \%$. Compared with YAG-2 \%wt $\mathrm{Al}_{2} \mathrm{O}_{3}$, YAG-5 \%wt and YAG-8 \%wt had low relative green density; it could be attributed to the inappropriate slurry viscosity and more porosity.

Fig. 9 shows the SEM images of $\mathrm{YAG} / \mathrm{Al}_{2} \mathrm{O}_{3}$ ceramics with different percentages of alumina nanoparticles in the YAG matrix. In the sample with $8 \%$ wt alumina, the reinforcement phase was distributed non-uniformly and accumulated in some parts of the sample, as shown in Fig. (9 a). Alumina was mainly located at the grain boundaries or triple points in the samples containing 2 and $5 \% \mathrm{wt}$ alumina. It was distributed uniformly throughout the body, as shown in Fig. $\mathbf{9}$ (b and $\mathbf{c}$ ). According to the SEM images and relative density (see Fig.8), the optimum amount of alumina should be less than $5 \%$ wt 
because it could be more homogeneous in structure. Based on evidence, when the alumina particles were in the boundary, the grain boundary was pinned, and alumina particles entered the structure through the grain boundary and improved the mechanical properties [35,36].

\subsection{Mechanical properties of the sintered body}

Table. 1 summarizes the hardness and elastic modulus values of all ceramic samples. Using alumina nanoparticles as a reinforcing agent increased the hardness as well as elastic modulus, as compared to the pure YAG ceramic. This was probably due to the higher elastic modulus of alumina phase in comparison to the YAG matrix. By increasing the alumina nanoparticles in the YAG matrix, because the hardness of alumina was higher than that of YAG, the maximum penetration depth $\left(h_{\max }\right)$ was decreased. As it is evident from Fig. (9 a), in the sample with 8 \%wt alumina, hardness at three points differed greatly due to the accumulation of alumina and the absence of the homogeneous distribution in the parts of the ceramic microstructure. Based on the results obtained from the SEM images, as shown in Table 1, with values less than $5 \%$ wt alumina, the reinforcing phase was almost uniformly distributed in the matrix, increasing the hardness up to 7.3\%. Despite the fact that YAG ceramic, in its turn, could be a suitable choice for many applications, it has poor mechanical properties. Therefore, in this study, the alumina phase was added to the YAG matrix in order to enhance the mechanical properties.

\section{Conclusions}

To summarize, in this study, the addition of alumina nanoparticles to the YAG matrix increased the mechanical properties of the YAG ceramics. Yttrium aluminum garnet powder was obtained by the particular wet chemical method at the lowest temperature of $1550{ }^{\circ} \mathrm{C}$. The slurries of the $\mathrm{YAG} / \mathrm{Al}_{2} \mathrm{O}_{3}$ nanocomposite with the solid loading of $75 \mathrm{wt} \%$ at the lowest viscosity (8 mPa.s) were prepared with 3Dmixture in the course of $9 \mathrm{~h}$. Using the nanocomposite powder and only $1 \mathrm{wt} \%$ of Dolapix increased the relative density of the green body up to $65 \%$; the final relative density of the body after sintering with no pressure at $1700{ }^{\circ} \mathrm{C}$ for $12 \mathrm{~h}$ was about $99.5 \%$. The optimum amount of alumina nanoparticles was less than $5 \mathrm{wt} \%$ due to the uniformity and absence of agglomeration in the ceramic microstructure.

\section{References}

[1] S. Ochiai, T. Ueda, K. Sato, M. Hojo, Y. Waku, N. Nakagawa, S. Sakata, A. Mitani, T. Takahashi, Deformation and fracture behavior of an $\mathrm{Al}_{2} \mathrm{O}_{3} / \mathrm{YAG}$ composite from room temperature to $2023 \mathrm{~K}$, Compos. Sci. Technol. 61 (2001) 2117-2128.

[2] T. Parthasarathy, T. Mah, L.E. Matson, Processing, structure and properties of alumina-YAG eutectic composites, J. Ceram. Process. Res. 5 (2004) 380-390.

[3] P. Palmero, A. Simone, C. Esnouf, G. Fantozzi, L. Montanaro, Comparison among different sintering routes for preparing alumina-YAG nanocomposites, J. Eur. Ceram. Soc. 26 (2006) 941-947. 
[4] R. Torrecillas, M. Schehl, L.A. Diaz, J.L. Menendez, J.S. Moya, Creep behaviour of alumina/YAG nanocomposites obtained by a colloidal processing route, J. Eur. Ceram. Soc. 27 (2007) 143-150.

[5] R. Lach, K. Wojteczko, A. Dudek, Z. Pędzich, Fracture behaviour of alumina-YAG particulate composites, J. Eur. Ceram. Soc. 34 (2014) 3373-3378.

[6] Y. Lv, W. Zhang, H. Liu, Y. Sang, H. Qin, J. Tan, L. Tong, Synthesis of nano-sized and highly sinterable Nd: YAG powders by the urea homogeneous precipitation method, Powder Technol. 217 (2012) 140-147.

[7] G.S. Corman, High-temperature creep of some single crystal oxides, in: 15th Annu. Conf. Compos. Adv. Ceram. Mater. Part 2 2, John Wiley \& Sons, 2009: p. 1745.

[8] A. Ikesue, T. Kinoshita, K. Kamata, K. Yoshida, Fabrication and optical properties of high-Performance polycrystalline Nd: YAG ceramics for solid-State lasers, J. Am. Ceram. Soc. 78 (1995) 1033-1040.

[9] K.A. Appiagyei, G.L. Messing, J.Q. Dumm, Aqueous slip casting of transparent yttrium aluminum garnet (YAG) ceramics, Ceram. Int. 34 (2008) 1309-1313.

[10] A.R. Studart, E. Amstad, M. Antoni, L.J. Gauckler, Rheology of concentrated suspensions containing weakly attractive alumina nanoparticles, J. Am. Ceram. Soc. 89 (2006) 2418-2425.

[11] F. Mohammadi, O. Mirzaee, M. Tajally, Influence of solid loading on the rheological, porosity distribution, optical and the microstructural properties of YAG transparent ceramic, Ceram. Int. 44 (2018) 12098-12105.

[12] X. Li, Q. Li, YAG ceramic processed by slip casting via aqueous slurries, Ceram. Int. 34 (2008) 397401.

[13] S. Ghazanfari, M. Torki, A. Shafeiey, M. Milani, R. Emadi, The influence of $\mathrm{Y}^{3+}$ and $\mathrm{Mg}^{2+}$ dopants on the transparency behavior of alumina ceramics, Mater. Chem. Phys. (2020) 122905.

[14] A. Shafeiey, M.H. Enayati, A. Al-Haji, The effect of slip casting parameters on the green density of $\mathrm{MgAl}_{2} \mathrm{O}_{4}$ spinel, Ceram. Int. 43 (2017) 6069-6074.

[15] A. Rahimian, M. Torki, S. Ghazanfari, B. Movahedi, R. Emadi, Effect of the Evolution of Rheological Behavior over Deagglomeration Time on Optical Transparency of Polycrystalline Alumina Ceramics, J. Ceram. Sci. Technol. 10 (2019).

[16] M.N. Rahaman, Ceramic processing, Wiley Online Library, 2006.

[17] C. Tallon, M. Limacher, G. V Franks, Effect of particle size on the shaping of ceramics by slip casting, J. Eur. Ceram. Soc. 30 (2010) 2819-2826. 
[18] J.M.F. Ferreira, H.M.M. Diz, Effect of solids loading on slip-casting performance of silicon carbide slurries, J. Am. Ceram. Soc. 82 (1999) 1993-2000.

[19] S. Çinar, S. Cinar, Rheological behavior of oxide nanopowder suspensions, (2013) 161.

[20] A. Krell, J. Klimke, Effects of the Homogeneity of Particle Coordination on Solid-State Sintering of Transparent Alumina, J. Am. Ceram. Soc. 89 (2006) 1985-1992.

[21] G. Kafili, M.R. Loghman-Estarki, M. Milani, B. Movahedi, The effects of TEOS on the microstructure and phase evolutions of YAG phase by formation of alumina/yttria core-shell structures, J. Am. Ceram. Soc. 100 (2017) 4305-4316.

[22] G. Kafili, B. Movahedi, M. Milani, A comparative approach to synthesis and sintering of alumina/yttria nanocomposite powders using different precipitants, Mater. Chem. Phys. 183 (2016) 136-144.

[23] A.S. for T. and M.C.B. on M.P. and M.P. Products, Standard Test Methods for Density of Compacted or Sintered Powder Metallurgy (PM) Products Using Archimedes' Principle, ASTM International, 2009.

[24] A. E2546, New standard practice for instrumented indentation testing, Indentation Stand. STD-62713, United States. (2007).

[24] X. Xu, M.I.L.L. Oliveira, R. Fu, J.M.F. Ferreira, Effect of dispersant on the rheological properties and slip casting of concentrated sialon precursor suspensions, J. Eur. Ceram. Soc. 23 (2003) 1525-1530.

[26] A. Dakskobler, K. Kočevar, T. Kosmač, Short-range repulsive potential developed by the addition of Mg (II) ions to aqueous alumina slurries, J. Eur. Ceram. Soc. 21 (2001) 2361-2368.

[27] J.A. Lewis, Colloidal processing of ceramics, J. Am. Ceram. Soc. 83 (2000) 2341-2359.

[28] E.M.M. Ewais, Rheological properties of concentrated alumina slurries: Influence of $\mathrm{pH}$ and dispersent agent, J. Australas. Ceram. Soc. 41 (2005) 36-43.

[29] B.A. Xuewei, L.I. Jiang, P.A.N. Yubai, L.I.U. Jing, B. JIANG, L.I.U. Wenbin, K.O.U. Huamin, G.U.O. Jingkun, Optimization of dispersing agents for preparing YAG transparent ceramics, J. Rare Earths. 31 (2013) 507-511.

[30] H. Watanabe, Critical rotation speed for ball-milling, Powder Technol. 104 (1999) 95-99.

[31] M.F. Zawrah, Investigation of lattice constant, sintering and properties of nano $\mathrm{Mg}-\mathrm{Al}$ spinels, Mater. Sci. Eng. A. 382 (2004) 362-370. doi:10.1016/j.msea.2004.05.074.

[32] J.-M. Kim, H.-N. Kim, Y.-J. Park, J.-W. Ko, J.-W. Lee, H.-D. Kim, Microstructure and optical properties of transparent MgAl2O4 prepared by Ca-infiltrated slip-casting and sinter-HIP process, J. Eur. Ceram. Soc. 36 (2016) 2027-2034. 
[33] F. Sommer, F. Kern, H.F. El-Maghraby, M.A. El-Ezz, M. Awaad, R. Gadow, S.M. Naga, Effect of preparation route on the properties of slip-casted Al203/YAG composites, Ceram. Int. 38 (2012) 48194826.

[34] S. Cinar, Rheological behavior of oxide nanopowder suspensions, (2013).

[35] C.-J. Wang, C.-Y. Huang, Y.-C. Wu, Two-step sintering of fine alumina-zirconia ceramics, Ceram. Int. 35 (2009) 1467-1472.

[36] L.C. Stearns, M.P. Harmer, Particle-Inhibited Grain Growth in Al203-SiC: I, Experimental Results, J. Am. Ceram. Soc. 79 (1996) 3013-3019.

\section{Tables}

Table 1: Comparison of mechanical properties of pure YAG ceramic with samples by different alumina

\begin{tabular}{|c|c|c|c|c|c|c|c|c|}
\hline \multirow{2}{*}{$\begin{array}{l}\text { Standard } \\
\text { deviation of } \\
\text { hardness }\end{array}$} & \multirow[t]{2}{*}{$\mathrm{h}_{\mathrm{f}} / \mathrm{h}_{\max }$} & \multirow[t]{2}{*}{$\mathrm{h}_{\max }(\mathrm{nm})$} & \multirow{2}{*}{$\begin{array}{l}h_{f} \\
(n m)\end{array}$} & \multirow{2}{*}{$\begin{array}{l}\text { Elastic } \\
\text { modulus } \\
\text { (Gpa) }\end{array}$} & \multicolumn{3}{|c|}{ Hardness (HV) } & \multirow[t]{2}{*}{ Sample } \\
\hline & & & & & 3 & 2 & 1 & \\
\hline 10.53 & 0.560 & 328.2 & 184.1 & 289 & 2237 & 2246 & 2225 & YAG \\
\hline 25.94 & 0552 & 319.7 & 176.6 & 309 & 2380 & 2330 & 2367 & $\begin{array}{l}\text { YAG-2 } \\
\% w t \\
\mathrm{Al}_{2} \mathrm{O}_{3}\end{array}$ \\
\hline 104.53 & 0.530 & 310.8 & 165.1 & 317 & 2325 & 2229 & 2438 & $\begin{array}{l}\text { YAG- } \\
5 \% \text { wt } \\
\mathrm{Al}_{2} \mathrm{O}_{3}\end{array}$ \\
\hline 1102.79 & 0.201 & 261.6 & 52.7 & 352 & 3868 & 7550 & 10839 & $\begin{array}{l}\text { YAG- } \\
8 \% \mathrm{wt} \\
\mathrm{Al}_{2} \mathrm{O}_{3}\end{array}$ \\
\hline
\end{tabular}

\section{Figures}




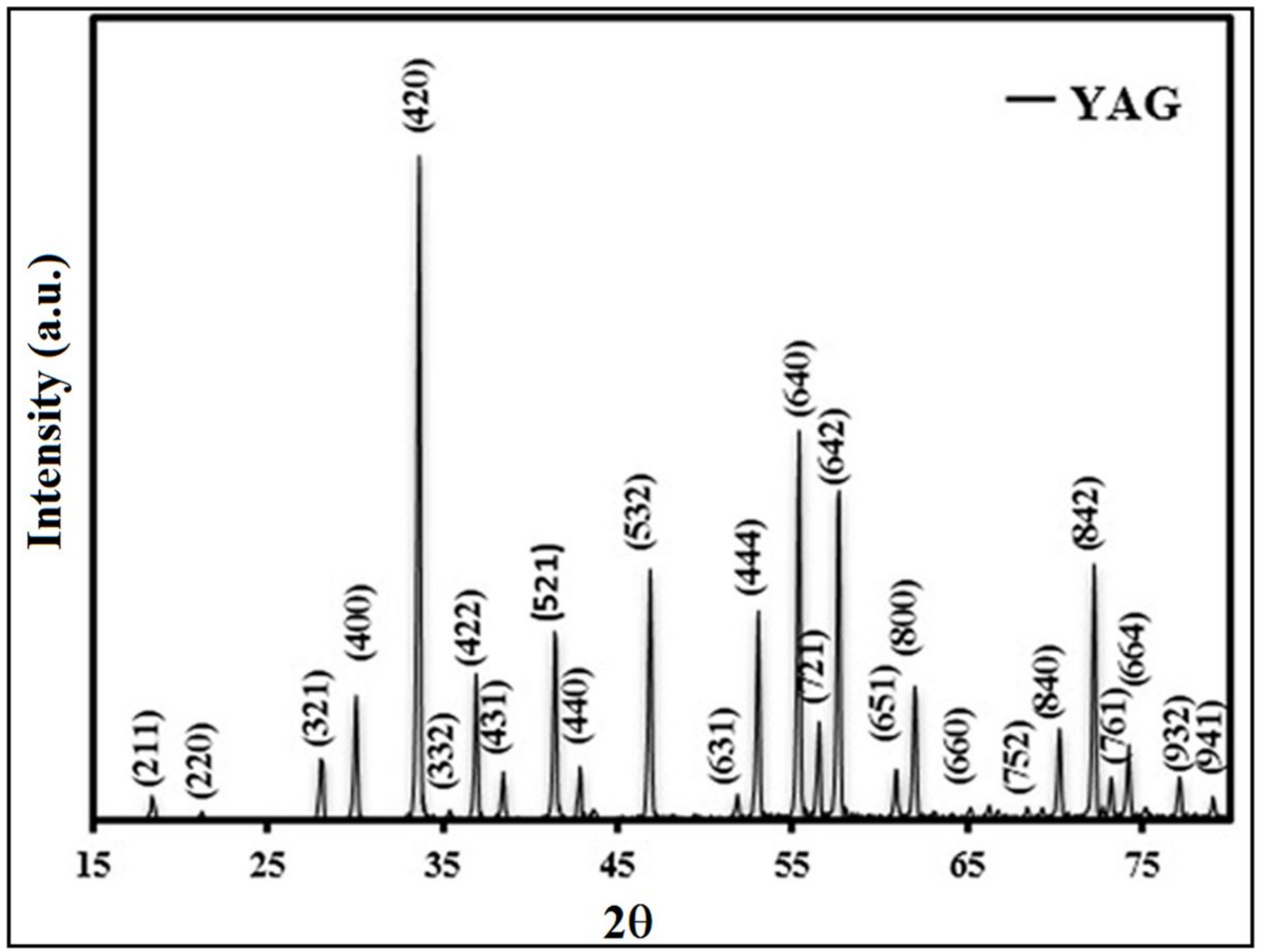

Figure 1

The X-ray diffraction pattern of the YAG powder at $1550^{\circ} \mathrm{C}$. 

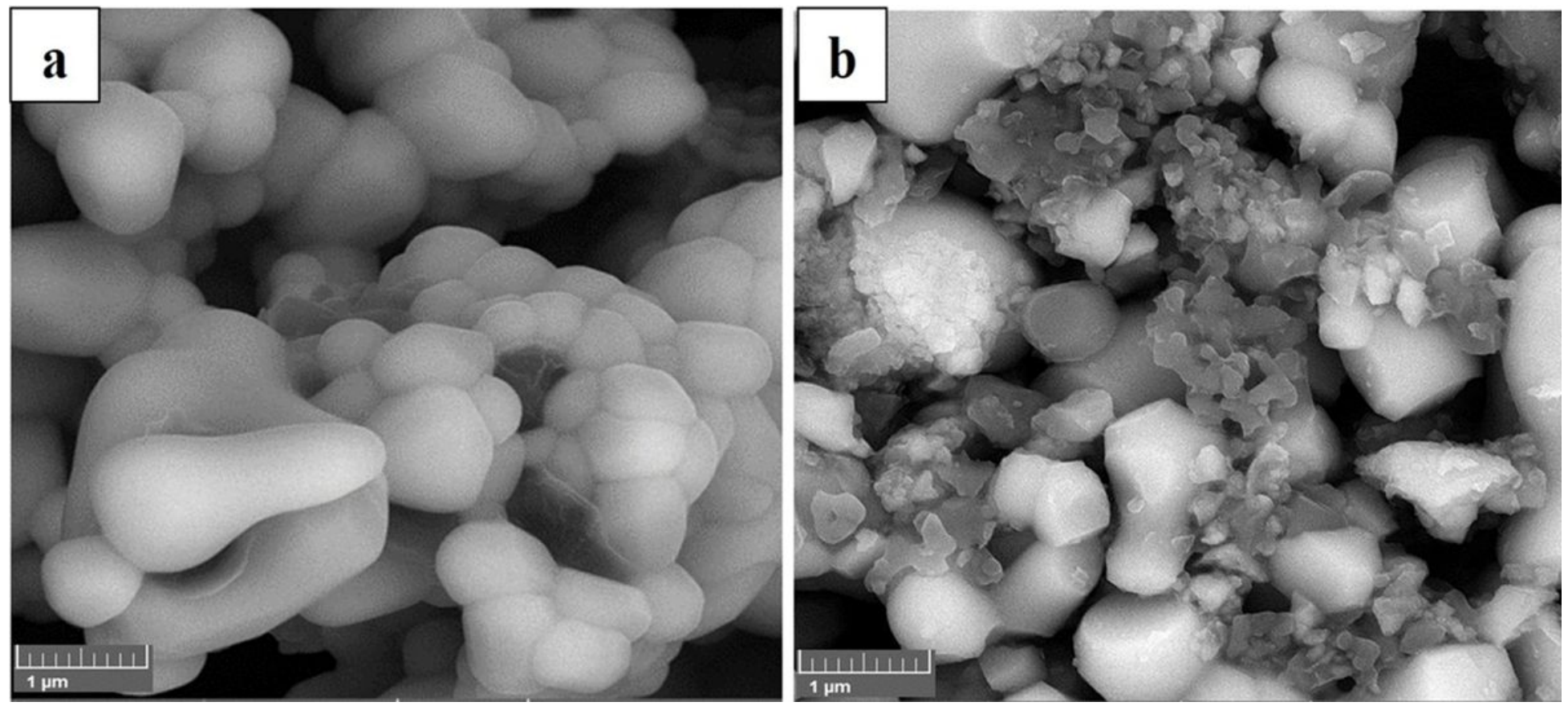

Figure 2

FESEM images of the YAG-Al2O3 nanocomposite powder: a) before ball-milling, b) after ball-milling.

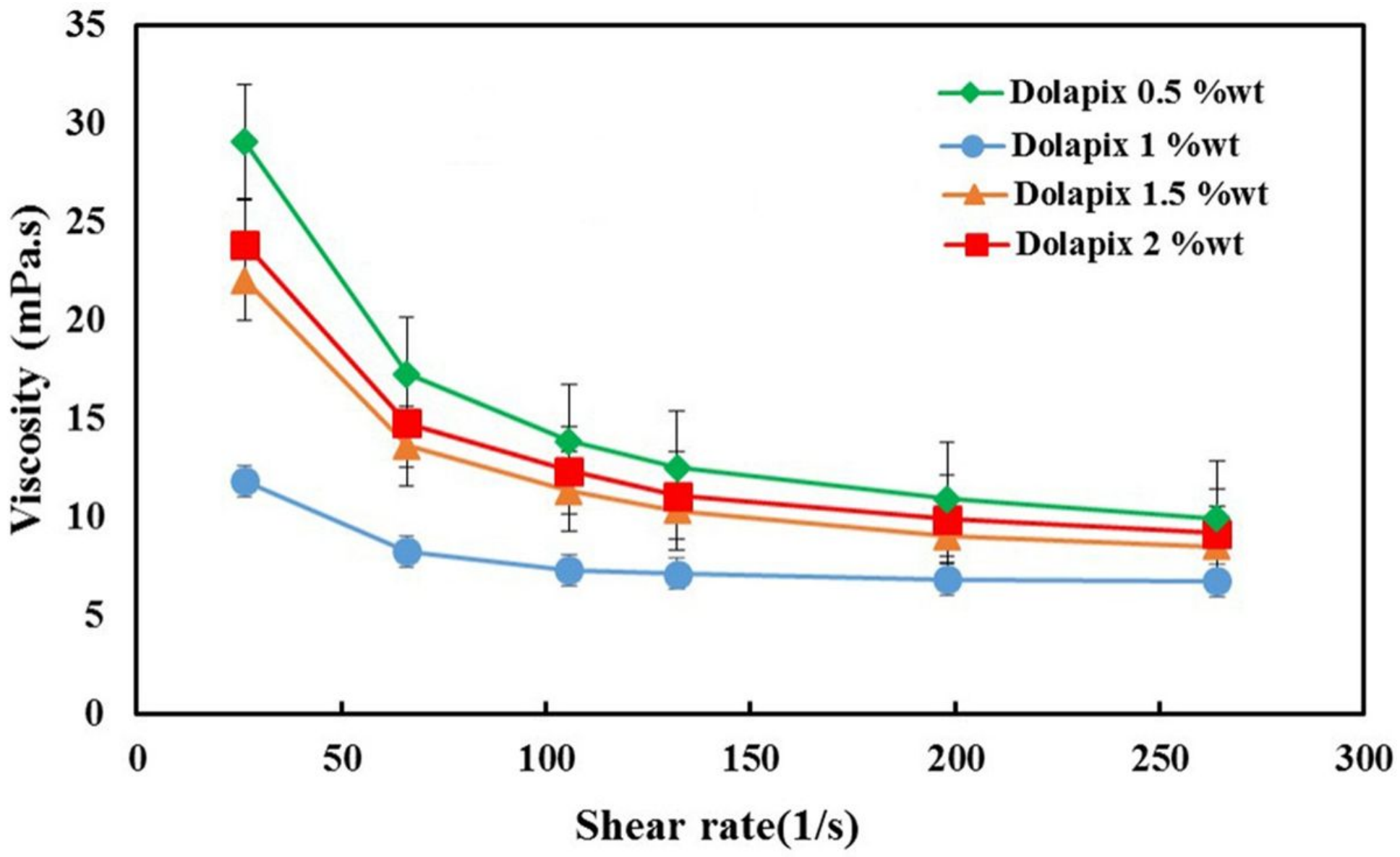

Figure 3 
The viscosity of $55 \%$ wt of YAG/Al2O3 nanocomposite slurries versus the shear rate at different dispersant percentages.

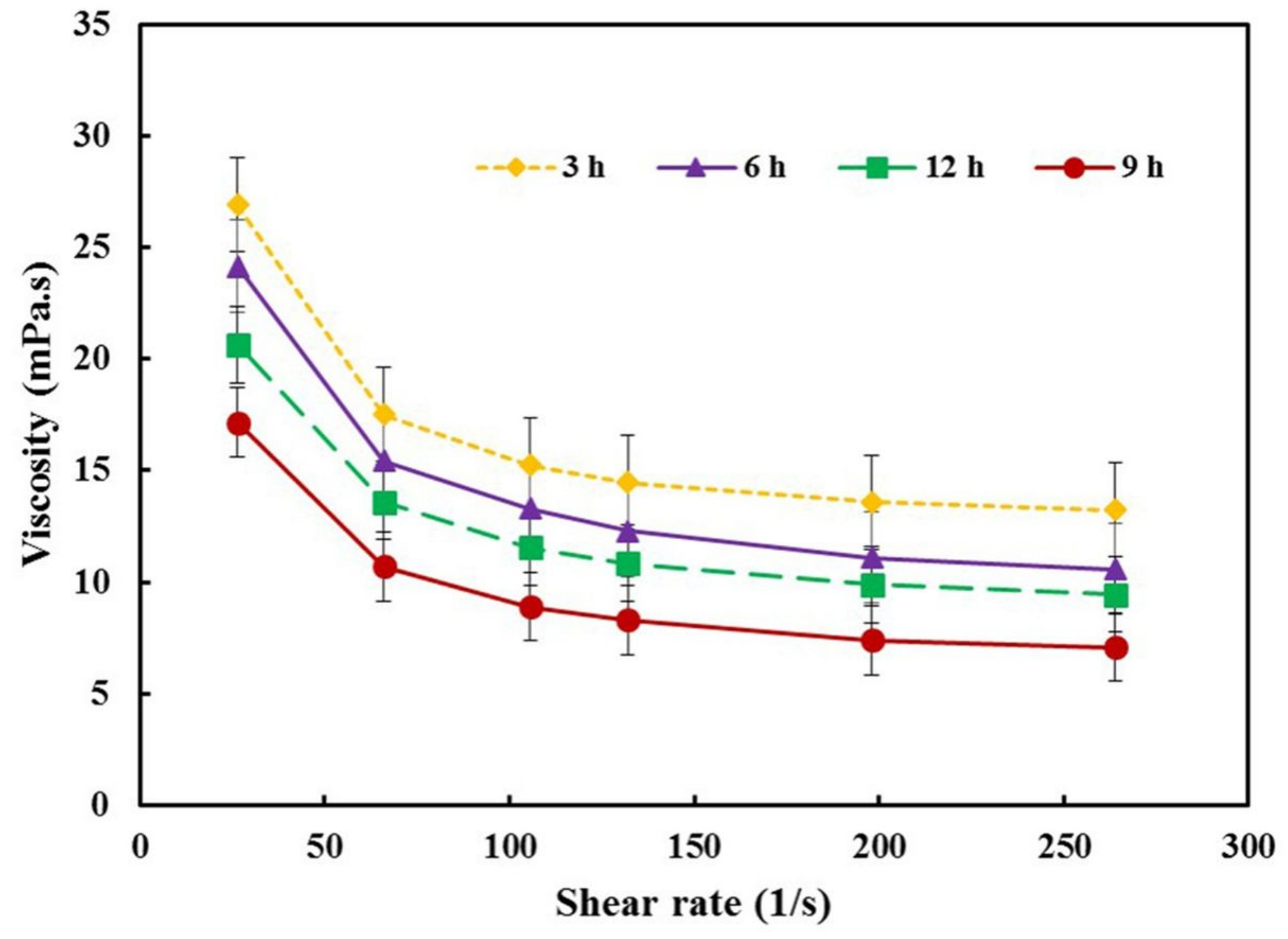

Figure 4

The viscosity of $55 \%$ wt of YAG/Al203 nanocomposite slurries versus the shear rate at different times. 


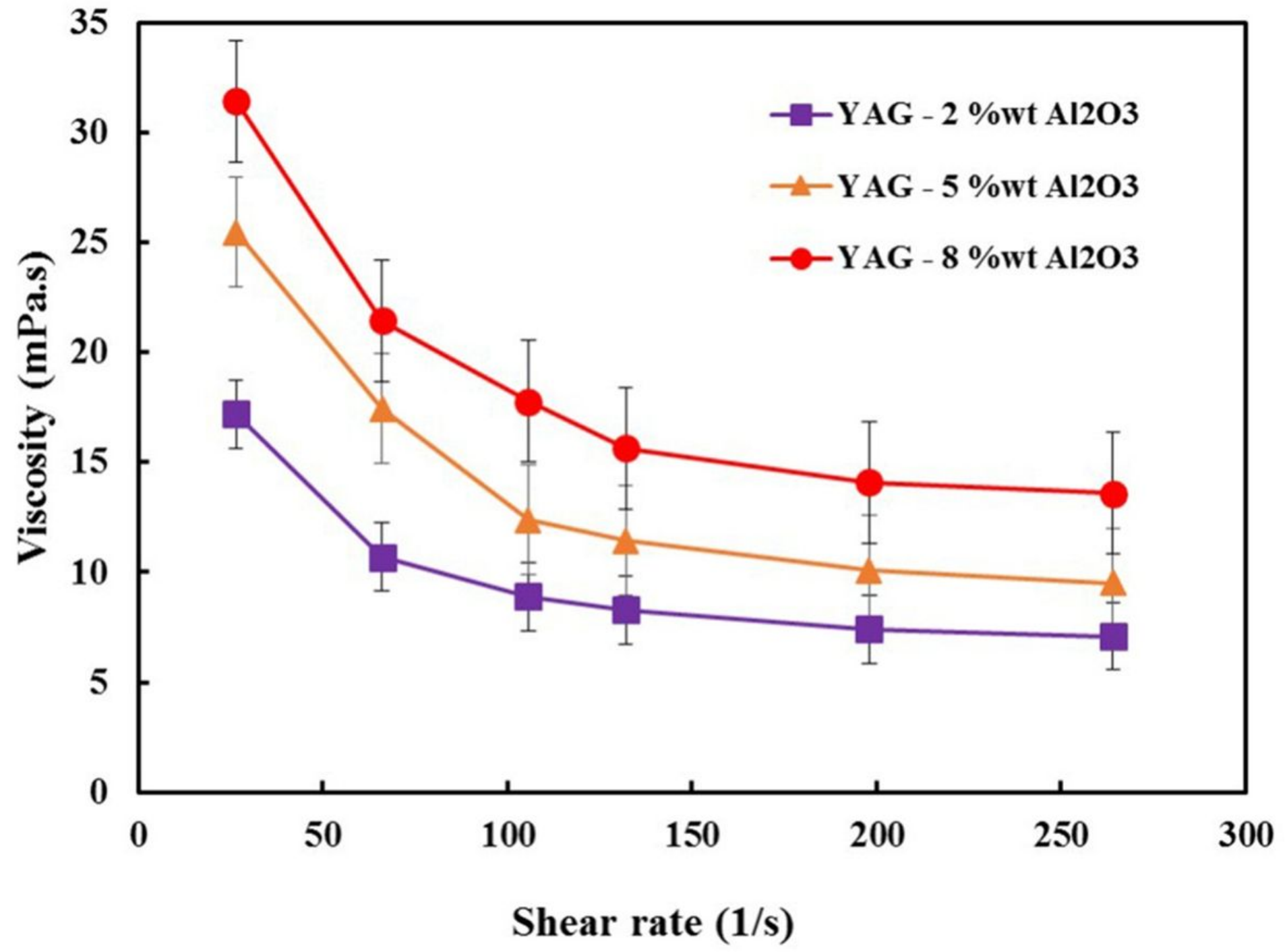

Figure 5

The viscosity of $55 \%$ wt YAG/2-8 \%wt Al2O3 nanocomposite slurries versus different shear rate. 


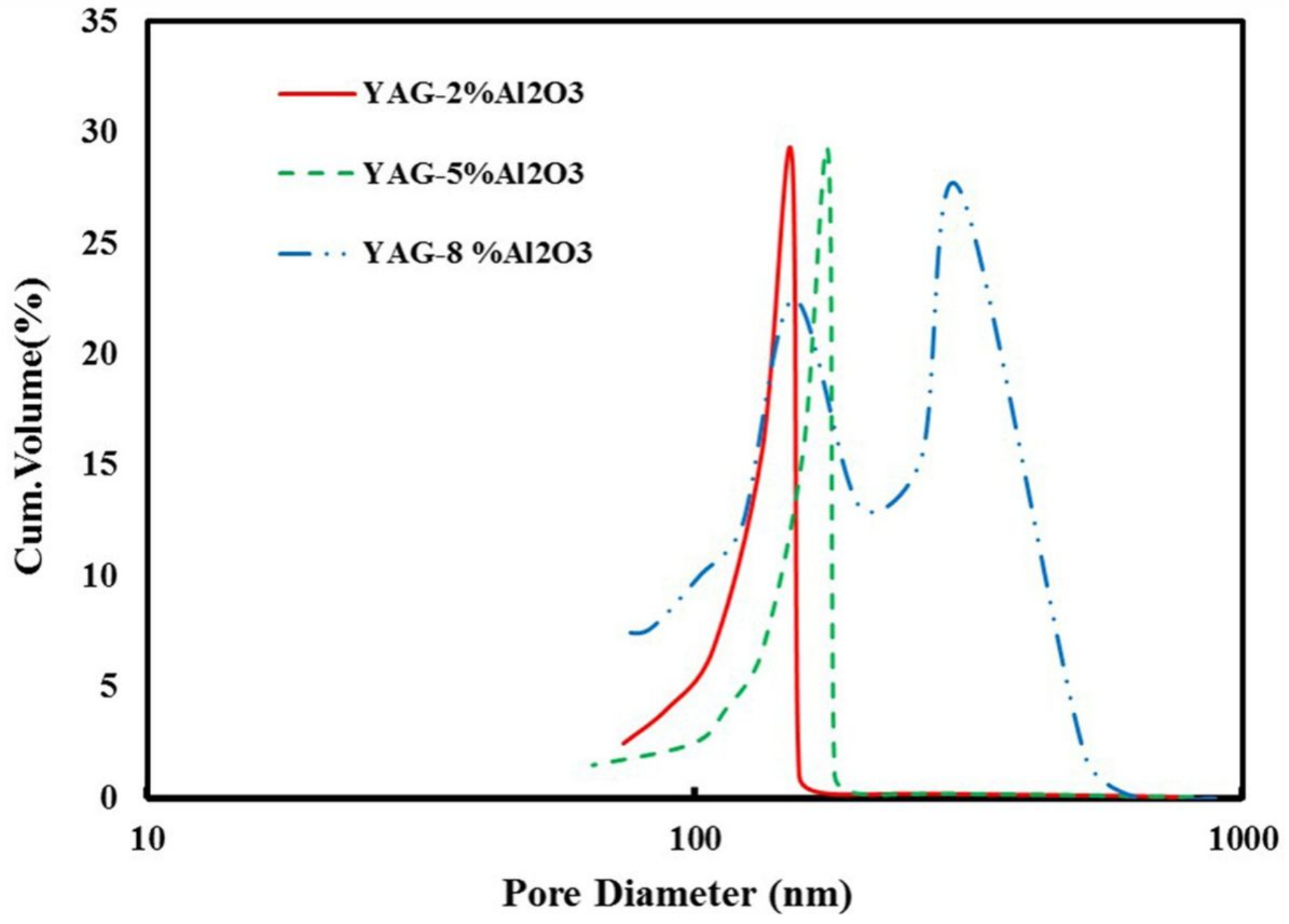

Figure 6

The pore size distribution of the green bodies obtained by slip casting for three different samples. 


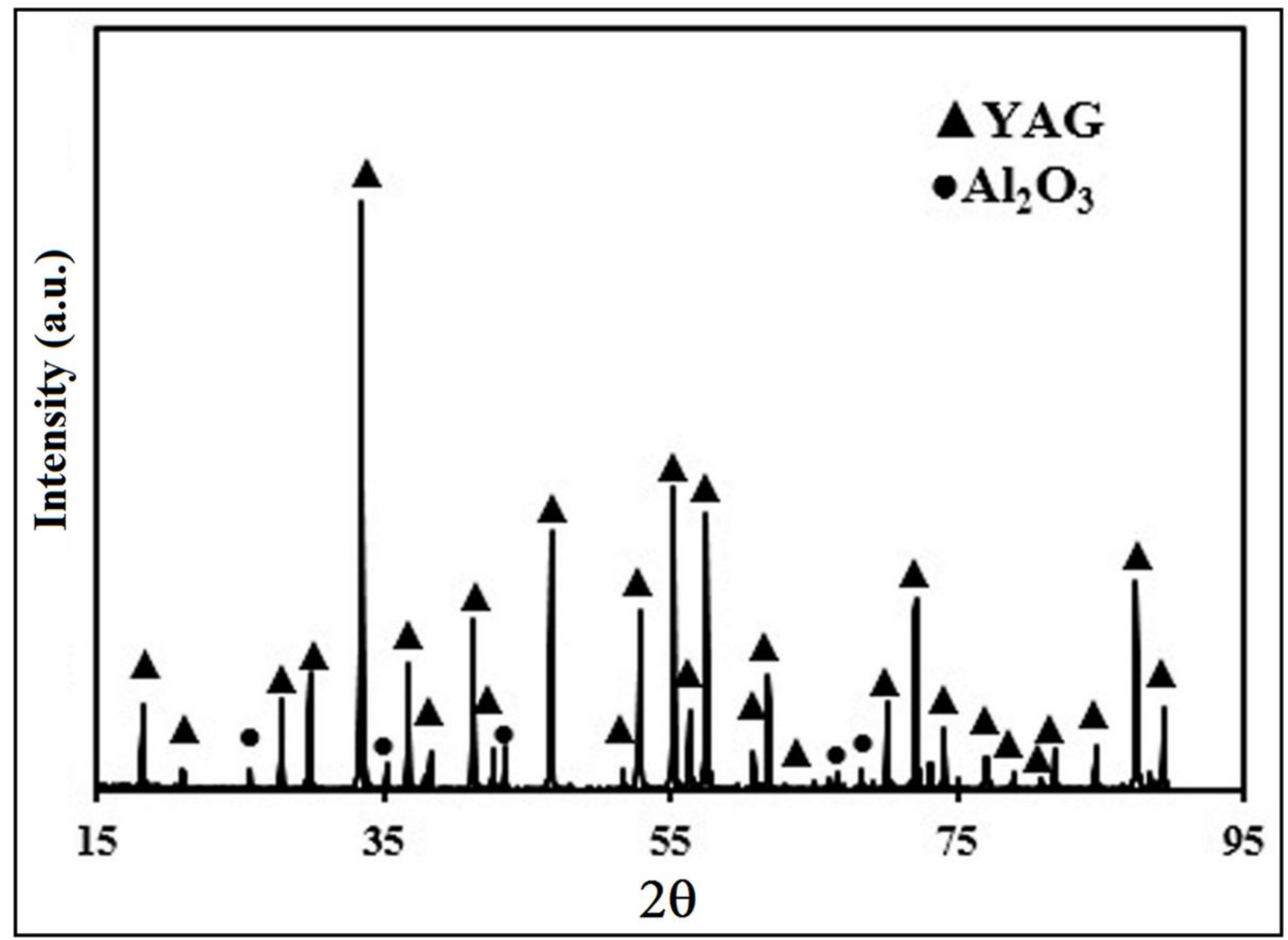

Figure 7

The XRD pattern of the sample YAG-Al2O3. 


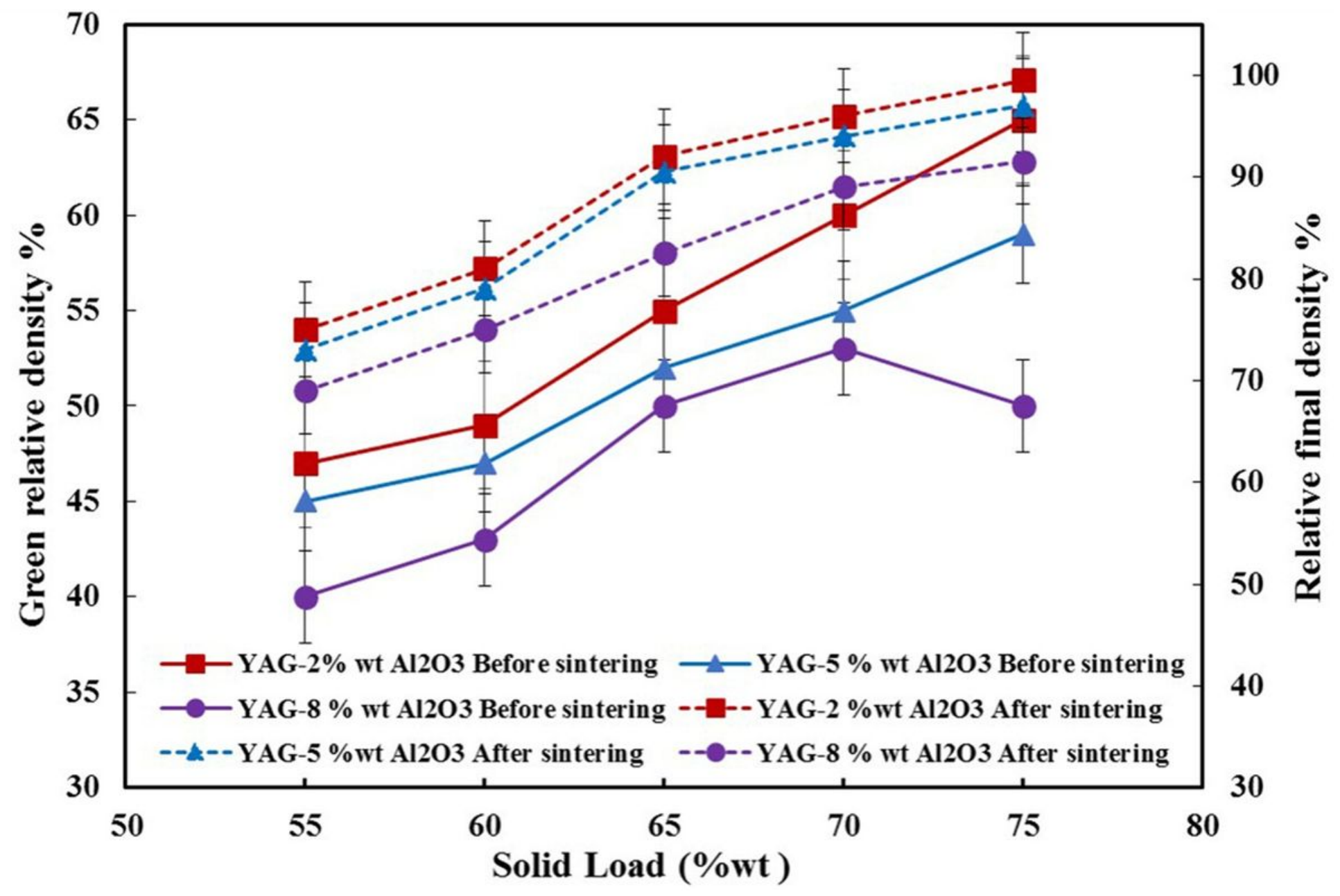

Figure 8

Relative densities of YAG/ 2-8 \%wt Al2O3 composites versus different solid loads. Before sintering at $600{ }^{\circ} \mathrm{C}$ and after sintering at 1700 . 

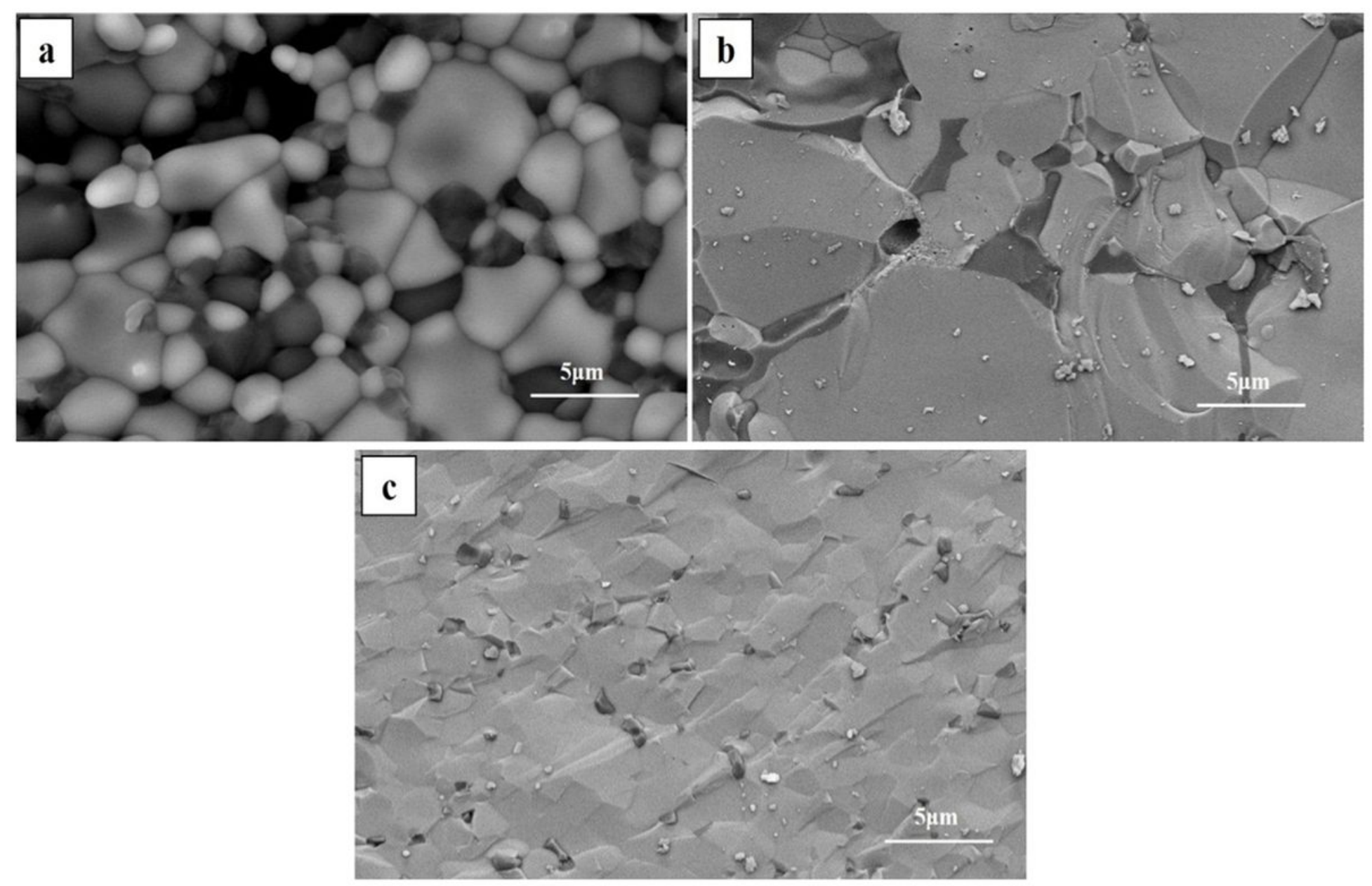

Figure 9

SEM images of YAG/Al2O3 ceramics with different percentages of alumina: a) $8 \% w t$ b) $5 \% w t$ c) $2 \% w t$ 